\title{
Early Development of Mushroom Bodies in the Brain of the Honeybee Apis mellifera as Revealed by BrdU Incorporation and Ablation Experiments
}

Dagmar Malun

Institut für Neurobiologie

Freie Universität Berlin

14195 Berlin, Germany

\section{Abstract}

In the honeybee the mushroom bodies are prominent neuropil structures arranged as pairs in the dorsal protocerebrum of the brain. Each mushroom body is composed of a medial and a lateral subunit. To understand their development, the proliferation pattern of mushroom body intrinsic cells, the Kenyon cells, were examined during larval and pupal stages using the bromodeoxyuridine (BrdU) technique and chemical ablation with hydroxyurea.

By larval stage 1, 40 neuroblasts are located in the periphery of the protocerebrum. Many of these stem cells divide asymmetrically to produce a chain of ganglion mother cells. Kenyon cell precursors underly a different proliferation pattern. With the beginning of larval stage 3, they are arranged in two large distinct cell clusters in each side of the brain. BrdU incorporation into newly synthesized DNA and its immunohistochemical detection show high mitotic activity in these cell clusters that lasts until mid-pupal stages. The uniform diameter of cells, the homogeneous distribution of BrdU-labeled nuclei, and the presence of equally dividing cells in these clusters indicate symmetrical cell divisions of Kenyon cell precursors.

Hydroxyurea applied to stage 1 larvae caused the selective ablation of mushroom bodies. Within these animals a variety of defects were observed. In the majority of brains exhibiting mushroom body defects, either one mushroom body subunit on one or on both sides, or three or four subunits (e.g., complete mushroom body ablation) were missing. In contrast, partial ablation of mushroom body subunits resulting in small Kenyon cell clusters and peduncles was observed very rarely. These findings indicate that hydroxyurea applied during larval stage 1 selectively deletes Kenyon stem cells. The results also show that each mushroom body subunit originates from a very small number of stem cells and develops independently of its neighboring subunit.

\section{Introduction}

The mushroom bodies of insects are thought to play a major role in processing and storage of chemosensory information (Menzel et al. 1974, 1994; Erber et al. 1980; Heisenberg et al. 1985; Davis 1993; de Belle and Heisenberg 1994; Hammer and Menzel 1995). This notion was based originally on the fact that the main input to the mushroom bodies comes from the antennal lobes, the first central station in the olfactory pathway. The participation of mushroom bodies in olfactory learning and memory was subsequently more directly investigated particularly in fruitflies and honeybees using various experimental techniques and simultaneous examination of behavioral responses to trained odor stimuli. One approach used electrophysiological methods to characterize neurons taking part in neuronal circuits of the mushroom bodies in the honeybee (Hammer 1993; Mauelshagen 1993). Recordings from two identified neurons (VUMmx1 and PE1) during olfactory conditioning demonstrated their participation in nonassociative and associative olfactory learning. In

LEARN IN G \& MEM ORY 5:90-101 @ 1998 by Cold Spring Harbor Laboratory Press ISSN 1072-0502/98 \$5.00

$$
\begin{array}{llllllllllllllll}
L & E & A & R & N & I & N & G & \underset{90}{\mathbf{X}} & M & E & M & O & R & Y
\end{array}
$$


another approach, temporary blocking of mushroom body function of honeybees through local cooling led to retrograde amnesia during the period of a few minutes following olfactory learning (Menzel et al. 1974; Erber et al. 1980). Furthermore, mushroom body structural mutants obtained by a genetic approach in Drosophila exhibit impaired olfactory learning and memory (Heisenberg et al. 1985; Davis and Dauwalder 1991; Skoulakis et al. 1993; for review, see Davis 1993). Also in Drosophila, an ablation procedure has been established to selectively delete mushroom bodies (de Belle and Heisenberg 1994). Classical conditioning of these animals demonstrated that mushroom bodies mediate associative odor learning in flies. Taken together, these results indicate a central role of mushroom bodies in learning and memory.

The mushroom bodies are also characterized by their neuronal plasticity during development and even during early adult life. Studies on the metamorphosis of the mushroom bodies in Drosophila demonstrated that reorganization in the periphery (e.g., complete degeneration and replacement of olfactory sense organs) during pupation parallels extensive neural reorganization of Kenyon cell processes within the mushroom bodies (Technau and Heisenberg 1982). In adult flies, vision affects the volume of mushroom bodies as was shown recently by Barth and Heisenberg (1997). Mushroom bodies in honeybees are also structurally highly plastic in adult life (Withers et al. 1993; Fahrbach et al. 1995a). Durst et al. (1994) found that the transition of nursing bees to foraging bees 7-10 days after emergence is accompanied by a drastic volume change of the calyx regions. These structural plasticities are indicative of synaptic reorganization at the input side of the mushroom bodies and may reflect the connectivity adaptions related to learning processes in foraging bees.

For further clarification of the function of mushroom bodies of honeybees, its selective elimination as described for Drosophila would be beneficial. How ever, for obvious reasons, the honeybee is not as easily accessible for genetic experiments as Drosophila. Thus, a manipulation of mushroom body size and structure by interference with its ontogenetic development might be promising. So far, no successful attempt was made to eliminate mushroom bodies during development as was performed in Drosophila (de Belle and Heisenberg 1994). To achieve precise and selective mushroom body ablation by this method, the ori- gin of the intrinsic cells, the Kenyon cells that form the mushroom bodies (Kenyon 1896), and the temporal proliferation pattern of Kenyon precursor cells need to be explored. Thus, in a first approach of this study, the mitotic activity in larval stages was examined using the BrdU technique. Although the exact number of origin Kenyon cell neuroblasts could not be identified by this method, the approximate time period (larval stage 1) of the onset of Kenyon cell proliferation was determined. In a second approach, the DNA synthesis inhibitor hydroxyurea was applied to larvae in this time frame.

Defects induced in the bee differ from those described for Drosophila in many respects. These differences are likely to be ow ing to the number of origin Kenyon cell neuroblasts, to their proliferation pattern, and to the overall structural organization of mushroom bodies in bees and flies. The results of this study also show that in honeybees selective mushroom body ablation with hydroxyurea is a feasible method that provides the opportunity to test the involvement of mushroom bodies in nonassociative and associative behavioral paradigms.

Some of the results have been published in abstract form (Malun 1997).

\section{Materials and Methods}

\section{TOLUIDINE BLUE STAINING}

Histological staining was performed on brain tissue of worker honeybees (Apis mellifera carnica) obtained from regular hives. The developmental stage of animals was determined according to Bertholf (1925). Brains were dissected under bee saline ( $130 \mathrm{~mm} \mathrm{NaCl}, 6 \mathrm{~mm} \mathrm{KCl}, 2 \mathrm{~mm} \mathrm{MgCl}$, $7 \mathrm{~mm} \mathrm{CaCl} 2,160 \mathrm{~mm}$ glucose, $10 \mathrm{~mm}$ HEPES at $\mathrm{pH}$ 6.7 and 500 mOsmoles; all chemicals are from Sigma, Deisenhofen, Germany) from the head capsule, immersed in fixative solution [2.5\% ( $\mathrm{wt} / \mathrm{vol})$ glutaraldehyde in phosphate buffer at $\mathrm{pH}$ 7.1] overnight at $4^{\circ} \mathrm{C}$, rinsed in buffer, and postfixed in $1 \%$ $\mathrm{OsO}_{4}$ for $1 \mathrm{hr}$ at room temperature. The tissue was subsequently dehydrated and embedded in Durcupan (Fluka, Buchs, Switzerland). Serial sections ( $5 \mu \mathrm{m}$ thick) were cut with a microtome (Om U3 ultramicrotome, Reichert) and stained with toluidine blue. The sections were embedded in EntelIan (Merck, Darmstadt, Germany) and examined with a microscope (Polyvar, Reichert-jung). Serial reconstructions of the sectioned tissue were carried out to perform cell counts.

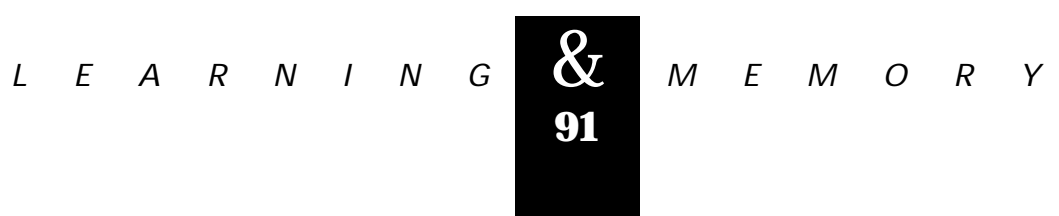


BRDU INCORPORATION

AND IMMUNOHISTOCHEMISTRY

To visualize DNA synthesis in dividing cells, 5-bromo-2'-deoxyuridine (BrdU, Sigma, Deisenhofen, Germany) was injected ( $2 \mu$ l of a $6.25-\mathrm{mg} /$

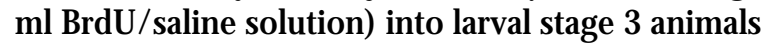
and older larvae and into pupae. Because the small size of animals of early larval stages (stage 1 and 2) precluded injections, these animals were fed with a BrdU solution [ $6.25 \mathrm{mg}$ of BrdU per $\mathrm{ml}$ of royal jelly/ $\mathrm{dH}_{2} \mathrm{O}$ solution (1:1)]. BrdU was allowed to incorporate 3-7 hr in larvae and 10-22 hr in pupae. Brains were dissected, fixed in $4 \%$ paraformaldehyde, embedded in paraplast, and cut into 5 - to $7-\mu m$-thick sections with a frontal orientation. Subsequently, using an immunohistochemical procedure, the sections were stained with a monoclonal antibody to BrdU (Amersham Buchler, Braunschweig, Germany) and a secondary antibody conjugated to Cy3 (Dianova, Hamburg, Germany). The sections were dehydrated, mounted with Entellan, and examined with a laser confocal microscope (see below).

\section{CONFOCAL MICROSCOPY}

Samples were examined with a confocal laser scanning microspope (Leica TCS-4D) equipped with a Leitz microscope (DM RBE) and a Krypton/ Argon laser light source. The Cy3 signal of the BrdU immunostaining was excited with the 568$\mathrm{nm}$ line of the Krypton/Argon laser and detected with the 590-nm long-pass filter. Single optical sections were scanned from 7- $\mu$ m-thick sections of the brain. Subsequently, some preparations were examined for their autofluorescence using an appropriate filter set (excitation wavelength, $515 \mathrm{~nm}$; barrier filters, 476 and $488 \mathrm{~nm}$ ). The autofluorescent signal of the aldehyde-fixed tissue emphasized the shape of cell clusters or regions of neuropil (Fig. 3D, below). Images showing the BrdU signal and the signal taken with autofluorescence helped to examine the position of mitotically active cells within the tissue. Figure panels were created in Adobe Photoshop, and photographs were taken with a slide maker (Lasergraphics Personal LFR Plus).

\section{ABLATION EXPERIMENTS}

Hydroxyurea selectively deletes dividing cells (Truman and Booker 1986; Prokop and Technau
1994). To ablate proliferating Kenyon cell neuroblasts, hydroxyurea at a concentration of $0.5-3.5$ $\mathrm{mg} / \mathrm{ml}$ of royal jelly/distilled $\mathrm{H}_{2} \mathrm{O}$ solution (1:1) was fed to stage 1 larvae for $5 \mathrm{hr}$ in multiw ells in a humid chamber at $35^{\circ} \mathrm{C}$. Control larvae were fed with royal jelly/distilled $\mathrm{H}_{2} \mathrm{O}$ solution only. After the treatment, the larvae were put back into the hive for further development. At different developmental stages, the brains were dissected and prepared for subsequent histological examination (PKAll immunohistochemistry; see below). Thirtysix animals showed mushroom body defects and were investigated in detail. Five animals were taken at larval stage 5, and 31 animals were taken either just after or up to 6 days after adult hatching.

\section{PKAII IMMUNOHISTOCHEMISTRY}

To emphasize the shape of the mushroom bodies but also that of other neuropil areas, immunohistochemistry was performed on 7- $\mu$ m-thick paraplast sections using a monoclonal antibody to the regulatory subunit of the CAMP-dependent protein kinase type II (PKAll; Müller 1997). As described in detail by Müller (1997), the PKAll was visualized using a primary monoclonal antibody (final dilution, 1:200), a biotinylated goat anti-mouse secondary antibody (final dilution, 1:2000; Boehringer, Ingelheim, Germany), and streptavidin-alkaline phosphatase (Sigma, Deisenhofen, Germany), 5-bromo-4-chloro-3-indolyl phosphate (AppliChem, Darmstadt, Germany), and blue tetrazolium (Sigma) as staining reagents.

\section{Results}

\section{BRDU STUDY AND TOLUIDINE BLUE STAINING}

In the adult honeybee brain, the mushroom bodies appear as prominent neuropil regions arranged as pairs in the dorsal protocerebrum (Fig. 1). Each mushroom body consists of 170,000 densely packed Kenyon cells (Witthöft 1967). The neuropil of each mushroom body is composed of tw o subunits: a pair of cup-shaped structures, the calyces, and two peduncles. Kenyon cell neurites within the bipartite peduncle divide to enter both the $\alpha$ - and the $\beta$-lobes, respectively (Mobbs 1982; Rybak and Menzel 1993). Thus, the lobes are fused products of Kenyon cell processes from both mushroom body subunits.

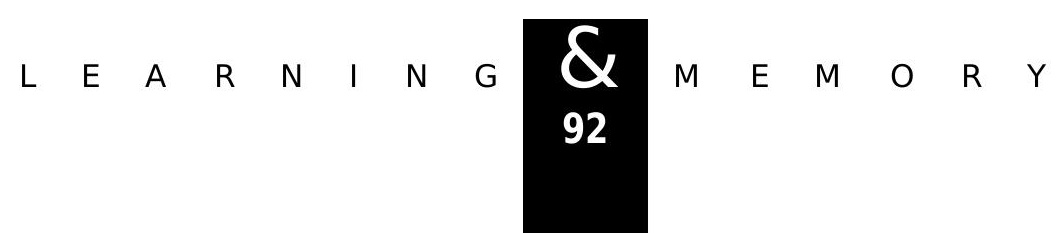




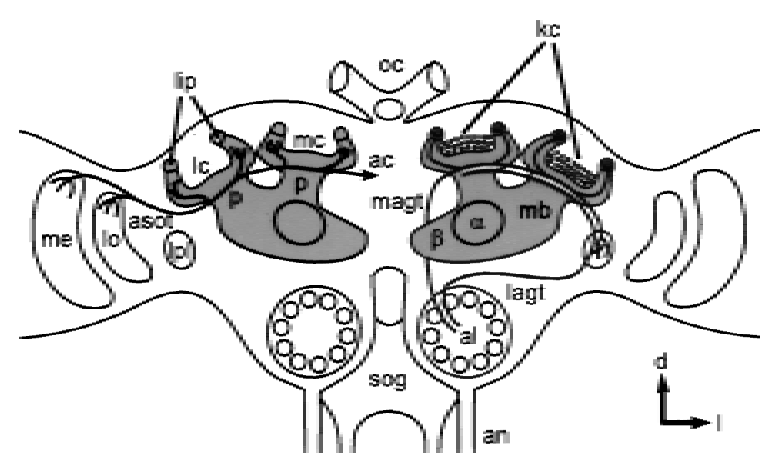

Figure 1: Schematic diagram of an adult honeybee brain in a frontal view. The paired mushroom bodies (shaded areas) consist of a medial $(\mathrm{mc})$ and a lateral calyx (Ic), a peduncle (p), and an $\alpha-(\alpha)$ and a $\beta$-lobe $(\beta)$. The somata of the Kenyon cells (kc) lie mainly in the center of the cup-shaped neuropils of the median and lateral calyces. The main input connections of the mushroom bodies are shown: Olfactory projection neurons from the antennal lobes (al) project via the medial antenno-glomerular tract (magt) exclusively to the lip region (lip) of the calycal neuropil and terminate within the lateral protocerebrum (Ipl). Projection neurons leaving the antennal lobe within the lateral antennoglomerular tract (lagt) innervate the lateral protocerebrum and the calyces. Visual fiber tracts originating in the optic lobes [medulla (me); lobula (lo)] project into both brain hemispheres via the anterior commissure (ac) and innervate the collar of the calyces. (an) Antennal nerve; (sog) suboesophagylganglion; (oc) ocelli; (d) dorsal; (I) lateral. All following figures refer to the same orientation.

This study was devoted to examining the postembryonic proliferation pattern of neuroblasts, particularly of Kenyon cell neuroblasts, during development of the mushroom bodies. Neuroblasts were identified in toluidine blue-stained sections of larval brains as large chromatin-poor cells that were located predominantly in the periphery of the brain (Fig. 2B, larval stage 3). In stages 1, 2, and 3 , the only stages examined for cell counts ( $\mathrm{n}=2$ 4 for each stage), 40 large neuroblasts with a diameter of $\sim 20 \mu \mathrm{m}$ were found per brain hemisphere within the protocerebrum. Sections of BrdU-treated larvae show ed labeled nuclei of some stem cells as early as stage 1 indicating their mitotic activity (Fig. $3 A, B$ ). Daughter cells were smaller in diameter $(\sim 8 \mu \mathrm{m})$ than the stem cells from which they derived. These findings together with the above-mentioned constant number of large neuroblasts in different larval stages indicate that these stem cells reproduce themselves and that the small daughter cells are products of an asymmetrical cell division (Fig. 2B). According to Edwards (1969),
Doe and Goodman (1985), and Truman and Bate (1988), in the insect nervous system, the progeny of neuroblasts that are generated by this type of cell division are called ganglion mother cells. A characteristic feature of this proliferation pattern is that ganglion mother cells are arranged in columns just underneath the stem cells (Zacharias et al. 1993). In the protocerebrum of bees, this pattern of large neuroblasts associated with columns of ganglion mother cells appeared with the beginning of larval stage 2 (Fig. 2B).

By larval stage 2, a distinct cell cluster appeared within the dorsal protocerebrum of each brain hemisphere. This cell cluster was easily dis-
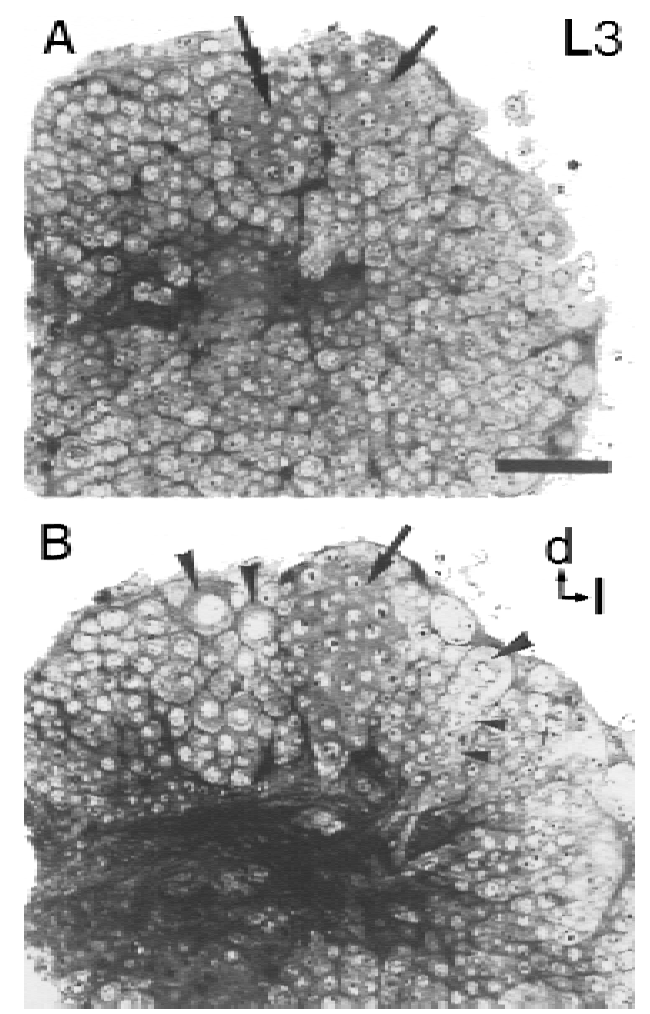

Figure 2: Toluidine blue-stained semithin plastic section of a brain at larval stage 3 . The dorsal protocerebrum of the right side of the brain is shown. $(A)$ Two cell clusters (arrows) that constitute the proliferation centers of Kenyon cells contain densely stained small neuroblasts of uniform diameter. (D ouble arrow) Left cell cluster; (arrow) right cell cluster. $(B)$ Ten micrometers deeper, the lateral cell cluster (arrow) reaches its greatest extension. Three large neuroblasts (large arrowheads) are located in the periphery of the protocerebrum. O ne large neuroblast gives rise to a column of smaller ganglion mother cells (small arrowheads). (d) Dorsal; (I) lateral. Scale bar, $50 \mu \mathrm{m}$. 
Figure 3: Confocal micrographs of paraffin sections through larval brains after BrdU incorporation and anti-BrdU immunohistochemistry to visualize mitotic activity. $(A, B)$ Two consecutive sections of a larval stage 1 brain. BrdU immunofluorescence is visible in numerous cell nuclei including nuclei of large neuroblasts in the periphery of the protocerebrum (arrows in A). A large neuroblast performs asymmetric cell division that is not yet completed ( $B$, arrow). The large nucleus of the neuroblast is unlabeled, whereas the small nucleus of the ganglion mother has already entered $S$ phase of a further mitotic cycle. (Inset) The dividing neuroblast (arrow) at higher magnification. $(C, D)$ Right side of the brain at larval stage 2. Several BrdU -immunolabeled nuclei are concentrated within one cell group (arrow in $C$ ) that is also visible as a distinct cell group in confocal micrographs scanned for autofluorescence (arrow in $D)$. The cluster constitutes the medial proliferation center for Kenyon cells. Large neuroblasts in the periphery of the protocerebrum are indicated by arrowheads. $(E, F)$ By larval stage 4, two distinct cell clusters containing numerous BrdU-labeled nuclei (arrows) have arisen in each side of the protocerebrum. $(F)$ The tw o proliferation centers of the left brain hemisphere at higher magnification. Scale bars in $A, C$, and $F, 50 \mu \mathrm{m}$; in $B$ inset, $25 \mu \mathrm{m}$; in $E, 100 \mu \mathrm{m}$.
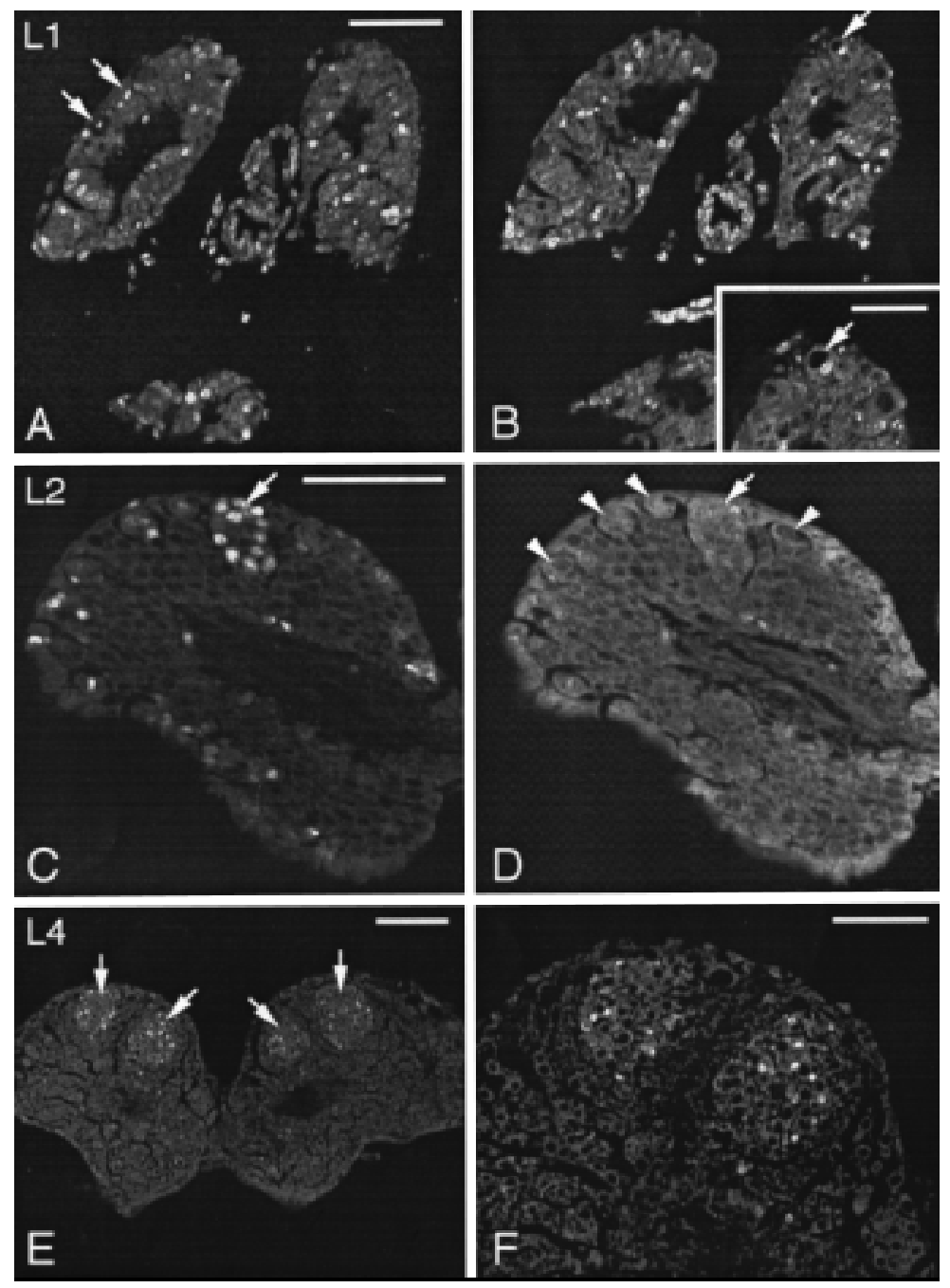

tinguished from the surrounding tissue by its tight conglomeration and by the great number of cells with BrdU-labeled nuclei (Fig. 3C,D). One larval stage later, a second cell cluster became visible laterally to, but in close apposition with, the first cluster (Figs. 2A,B and 3E,F). Because of their relative positions within the protocerebrum, they will be referred to as medial and lateral cell groups (Figs. 2A,B and 3E,F). These two cell groups constitute the proliferation centers of the Kenyon cells (this paper; Panov 1957). In toluidine blue-stained tissue, cells within these clusters had a uniform appearance with a homogeneous dark cytoplasm and a diameter of $\sim 10 \mu \mathrm{m}$ (Fig. $2 \mathrm{~A}, \mathrm{~B}$ ). Thus, they are smaller than the large neuroblasts in the periphery of the brain. Data gathered from both toluidine blue- and Bodian-stained sections and from BrdU immunolabeling revealed that the two cell clusters of each hemisphere persisted and show ed mitotic activity until mid-pupal stages (pupal stage 4; Fig. 4A,B).

Throughout larval and pupal development, these proliferation centers w ere never observed to be associated with large neuroblasts. This fact, together with the above-mentioned uniform size of the cells, and homogeneous distribution of BrdUstained nuclei within the cell groups strongly suggest that the Kenyon cell precursors undergo symmetrical cell divisions. This assumption is strengthened by findings gathered by classical cytology; in Bodian-stained brains, Kenyon cell precursors were observed regularly that divide equally (Fig. 4B). Because of their high mitotic activity and their proliferation pattern, I consider them as small neuroblasts that clearly differ from the large common neuroblasts in the periphery of the brain that perform asymmetric cell division and that are associated with columns or rows of their progeny. 


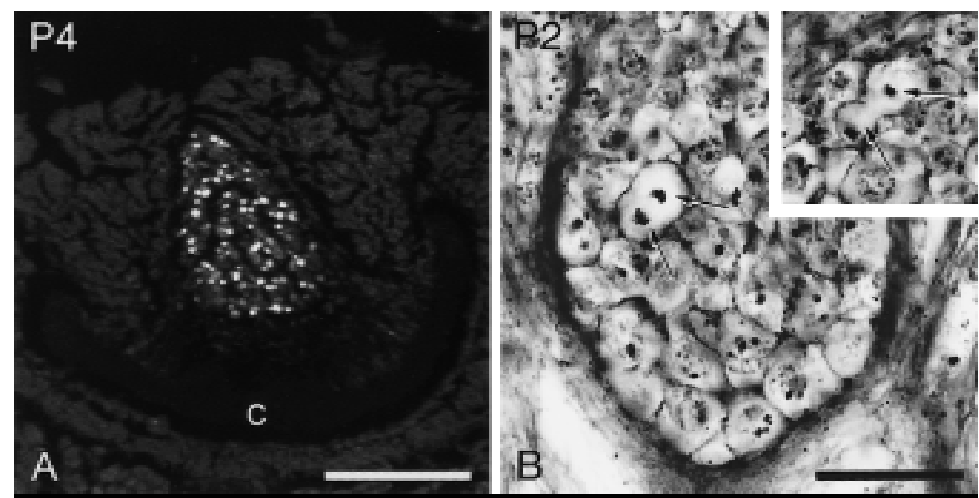

ter. The two daughter cells (arrows) are of equal diameter indicating symmetrical cell division. (Inset) Symmetrica dividing Kenyon cell precursors (arrows) during telophase of the mitotic cycle. Scale bar in $A, 100 \mu \mathrm{m}$; in $B, 25 \mu \mathrm{m}$.
Figure 4: Mitotic activity of Kenyon precursor cells in the mushroom body proliferation centers during pupal development. $(A)$ Confocal micrograph of a paraffin section through a brain at pupal stage 4 after BrdU incorporation and anti-BrdU immunohistochemistry to visualize mitotic activity. Numerous labeled nuclei are homogeneously distributed within the mushroom body proliferation center. (C) Developing calyx neuropil. (B) Bodian-stained sections of a brain at pupal stage 2 . Cell division (the anaphase of the mitocic cycle is shown) of Kenyon cell precursors occurs within the mushroom body proliferation cen-

\section{ABLATION EXPERIMENTS}

As shown above, larval stage 2 was the first stage in which Kenyon cell precursors were grouped in the medial cell clusters and were therefore clearly distinguishable from surrounding cells (Fig. 3C,D). At that time, only a small number of Kenyon precursor cells had been formed. The clusters consisted of $\sim 20$ cells. Thus, the preceding stage was most likely the stage in which the Kenyon cell neuroblasts began to proliferate. Therefore, I expected hydroxyurea application to be most effective in interfering with cell proliferation by stage 1 . Blockade of cell division at this early stage should cause strong ablation effects of mushroom bodies.

To obtain a precise picture of structural defects within the brain, a PKA immunostaining procedure was applied. The anti-PKA antiserum labels neuropil structures and particularly intensively, the mushroom body neuropil (Müller 1997). Although the overall intensity of the PKA immunostaining in the present study varied among animals, strong labeling was always observed within the neuropil of the mushroom bodies (Fig. 5). Thus, PKA immunolabeling provided a useful indicator for mushroom body defects. PKA immunostaining in untreated animals served as a control and reference to animals with hydroxyurea-induced ablation (Fig. $5 A)$.

Ablation of mushroom bodies was observed in 31 brains out of 37 hydroxyurea-treated animals that passed adult hatching. The adult eclosion rate depended on the hydroxyurea concentration applied. Highest viability (30\%) was observed in animals treated with low concentrations of hydroxy- urea, that is, $0.5-3.5 \mathrm{mg} / \mathrm{ml}$, which is below the concentrations used for chemical ablation of mushroom bodies in Drosophila (de Belle and Heisenberg 1994) and is the range of concentrations used for partial ablation of Drosophila mushroom bodies (Ito et al. 1997). Higher hydroxyurea concentration applied to stage 1 honeybee larvae resulted in considerable larval and pupal lethality. Three out of eight animals studied at larval stage 5 exhibited a normal mushroom body morphology, whereas five larvae showed mushroom body defects. All 45 animals (larvae and pupae) were studied in detail for hydroxyurea-induced defects. Size and external anatomy of animals exhibiting mushroom body defects were not distinguishable from control animals. No obvious adverse effects of the hydroxurea treatment outside of the brain were observed. The gross morphology, shape, and volume of brain structures other than the mushroom bodies (e.g., central complex, optic lobes, and antennal lobes) were not affected in the brains of hydroxyurea-treated animals (Fig. 5). This, however, does not exclude small defects (e.g., ablation of single cells or small neuropilar compartments) that would not have been detected with the histological examination used in this study. The presence or absence of the calyces is the most reliable indicator for mushroom body defects because the calyces are formed by the Kenyon cell dendrites and constitute morphologically prominent neuropil regions. Consequently, the ablation of Kenyon cell neuroblasts would be most likely reflected in morphological changes within the calyces and the peduncle of each calyx. The $\alpha$ - and $\beta$-lobes, however, are the fused structures of Kenyon cells from both the medial and the lateral calyx (Rybak and 
Malun

Figure 5: PKA immunostaining on paraffin sections of adult brains of a control animal $(A)$ and of hydroxyurea-treated animals $(B-F)$. Immunolabeling is present in all neuropilar areas but is especially strong in the mushroom bodies. $(A-C, E, F)$ Same levels of the brains from frontal serial sections. (D) A more anterior section. (A) Brain of a control animal. Strong PKA immunolabeling is found within the calyces of the mushroom bodies. $(B)$ The medial calyx of the left hemisphere is deleted. $(C)$ The medial calyces in both brain hemispheres are ablated. The calyces extend to the midline of the brain. The volume of the protocerebrum is reduced owing to the mushroom body ablation. $(D)$ The lateral and the medial calyces of the left hemisphere are ablated, whereas both calyces of the opposite hemisphere are present. The section shows the $\alpha$-lobe in the intact side and the complete absence of the $\alpha$-lobe in the hemisphere with mushroom body ablation. The protocerebrum without mushroom body is greatly reduced in its size. Although strong PKA immunostaining is detectable in all neuropil regions, the strongest labeling is found within the mushroom bodies. (E) O nly the lateral calyx of the right hemisphere is present. $(F)$ Brain with complete mushroom ablation. The immunostaining does not detect any parts of the mushroom bodies. The volume of the protocerebrum has greatly shrunk. (al) Antennal lobe; (Ic) lateral calyx; (ml) medial calyx; $\alpha, \alpha$-lobe. Scale bar, $500 \mu \mathrm{m}$.

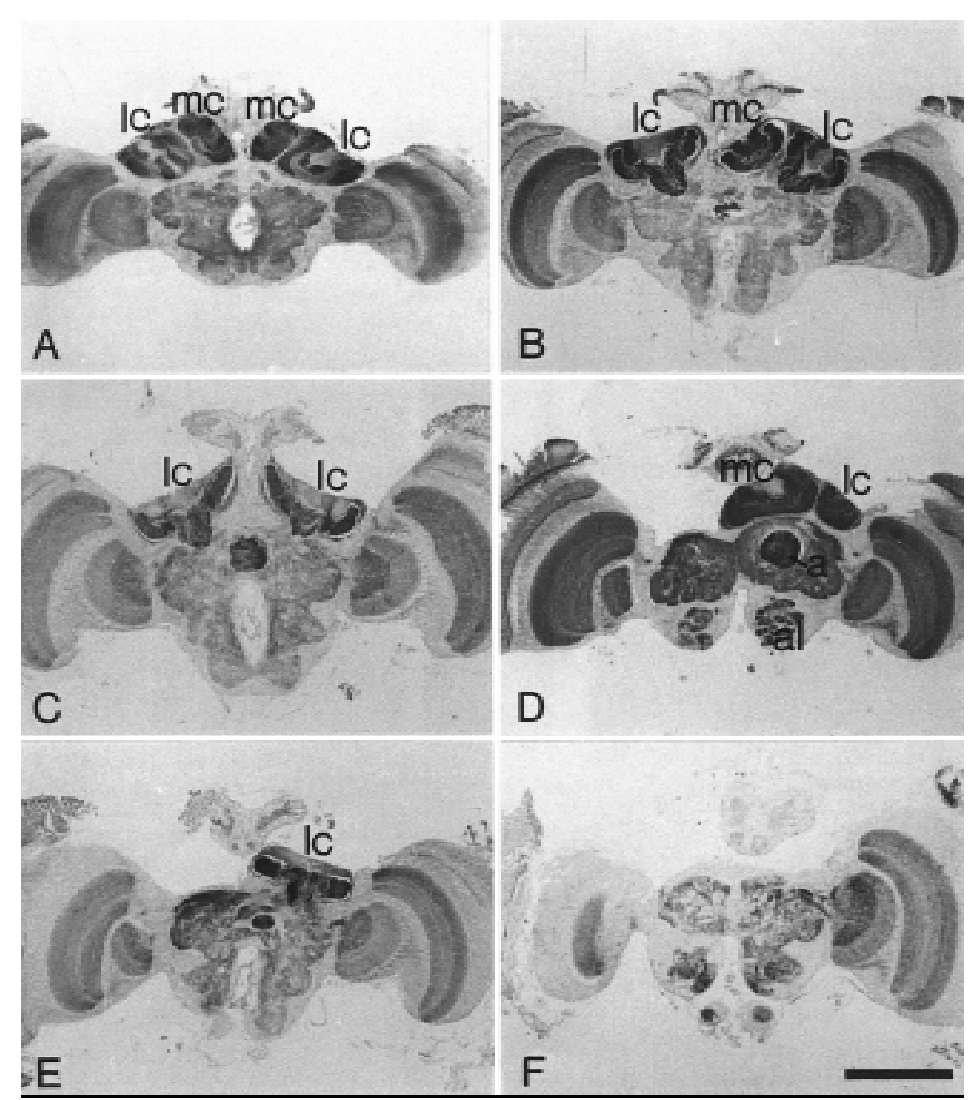

Menzel 1993) and could not contribute as unequivocal indicators for defects in individual mushroom body substructures. Mushroom body defects in larvae were characterized by the presence or absence of the mushroom body proliferation centers and the "calyx developmental zone" that comprises the precursor structure of the future calycal neuropil (Menzel et al. 1994). Thus, larvae showed a similar distribution of the various mushroom defects as adult animals, and therefore, findings on larvae were included into data gathered on adult animals.

The various mushroom body defects observed are grouped into five main classes and are summarized in Figure 6: (1) In one group of animals $(\mathrm{n}=10)$, the medial calyx in one hemisphere was completely absent (Fig. 5B). This became obvious by close examination of the level of the brain in which the lateral calyces show ed their greatest extension and their peduncles projected into the pro-

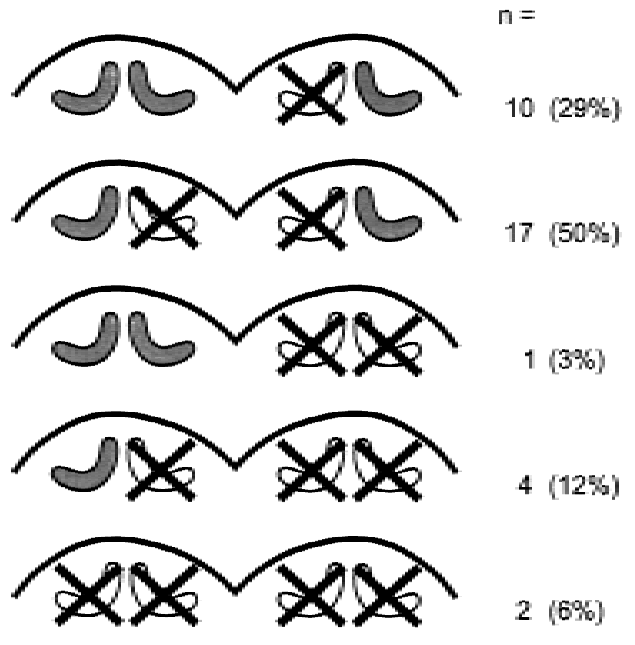

Figure 6: Schematic diagram of hydroxyurea-induced mushroom body defects indicated by the presence and absence (crossed out) of calyces of the mushroom bodies. Number of animals with each type of defects $(n)$ and their relative representation are shown.

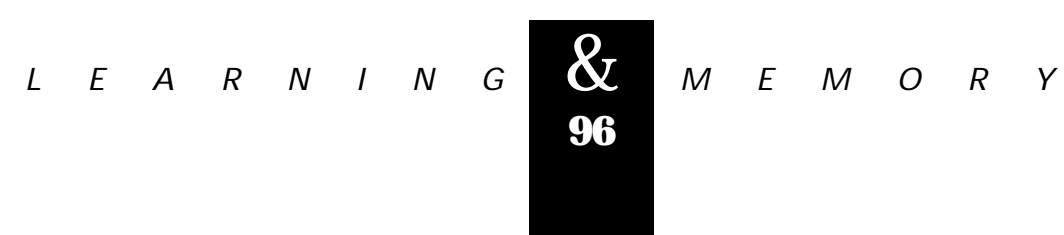


MUSHROOM BODY DEVELOPMENT IN THE HONEYBEE

tocerebral neuropil. Although only one calyx developed on one side, it had the same dimension as the corresponding lateral calyx on the opposite brain side. Furthermore, the position and the course of the peduncles were the same for both lateral calyces (Fig. 5B). In more anterior sections, the region in which the medial calyces reached their greatest extension, the medial calyx of the intact hemisphere lacked its counterpart on the other side of the brain. In the brain hemispheres with the medial calyx missing, the $\alpha$-lobe was greatly reduced (half the size of $\alpha$-lobes in control animals). Moreover, even the whole protocerebrum appeared decreased in size on one side, because the surface of protocerebral outline became flatter. (2) The majority of animals $(n=17)$ lacked the medial calyx in both hemispheres, whereas the lateral calyces appeared normal with respect to their size (Fig. 5C). How ever, in these brains the cup-shaped neuropil of the lateral calyces appeared flatter and extended into the region normally occupied by the medial calyx and even reached the midline of the brain. (3) The fact that the protocerebrum decreased in size by ablation of mushroom body subunits became even more obvious in brains with complete loss of a mushroom body in one brain side (Fig. 5D). The contralateral side developed the full set of calyces, peduncles, and lobes. These defects were observed very rarely $(\mathrm{n}=1)$. (4) Four animals had developed only one lateral calyx. The medial and lateral calyces of one and the medial calyx of the other hemisphere were completely missing (Fig. 5E). (5) Finally, two animals show ed a complete mushroom body ablation on both sides. Because the mushroom body in honeybees represents $10 \%$ of the total bee brain volume (Mobbs 1982), the protocerebrum of these animals had decreased considerably in size (Fig. 5F). Immunolabeling of PKAll for these animals did not provide any evidence for the existence of Kenyon cells.

In two animals (not listed in the diagram of Fig. 6), a partial ablation within mushroom body subunits was observed: One brain had developed just a small clump of presumptive Kenyon cells that did not give rise to a prominent calyx neuropil but formed just a very small, rudimentary peduncle (not shown). Another animal that was sacrificed and processed at the last larval stage (larval stage 5) had developed two cell clusters of Kenyon cell precursors in one side and a single cell cluster of smaller size within the opposite side (not shown).

\section{Discussion}

\section{KENYON PRECURSOR CELLS DIVIDE SYMMETRICALLY}

The present study did not succeed in determining the number of origin Kenyon cell neuroblasts that form the two proliferation centers of each side of the brain. Neither toluidine blue staining nor the BrdU technique revealed large neuroblasts on top of the Kenyon cell cluster that would give rise to ganglion mother cells via asymmetrical cell divisions and, subsequently, via a final symmetrical division, to a pair of Kenyon cells as described for developing mushroom bodies in Drosophila (Ito and Hotta 1992; Ito et al. 1997; Tettamanti et al. 1997). Possibly, Kenyon cells in honeybees do not derive from large conspicuous neuroblasts as in Drosophila but from smaller stem cells. A more reasonable explanation, however, would be that large origin Kenyon cell neuroblasts lying in the periphery of the brain begin to divide symmetrically very early during larval development (larval stage 1) and give birth to two identical small neuroblasts as it was shown for the monarch butterfly Danaus by Nordlander and Edwards (1970). By performing this proliferation pattern, the origin neuroblasts would exist just for a short period of time and, therefore, would be difficult to detect. Likewise, the uniform size of small mitotically active neuroblasts observed in the proliferation clusters as early as larval stage 2 strongly suggests that the small daughter neuroblasts that derive from origin neuroblasts also perform symmetrical cell divisions. The proliferation centers formed by these neuroblasts enlarge until late larval and early pupal stages and exhibit mitotic activity until mid-pupal stages, whereas neurogenesis is absent in the brains of adult honeybees (Fahrbach et al. 1995b; this paper). The proposed proliferation pattern can explain the development of the enormous number of 170,000 Kenyon cells in honeybees (Witthöft 1967). The findings of the present study are in agreement with data published by Panov (1957, 1960) who described two main types of proliferation patterns in the developing honeybee brain. Panov distinguished between (1) large neuroblasts that divide asymmetrically, thereby reproducing themselves and generating smaller ganglion mother cells that subsequently produce a pair of neurons in a symmetrical division, and (2) proliferation centers in which small neuroblasts divide symmetrically to produce small neuroblasts that in 
turn divide symmetrically. Panov further proposed that in honeybees, both proliferation patterns take place during the development of the optic lobes, whereas the Kenyon cells are generated exclusively by the second type of proliferation pattern. The latter observation was recently confirmed by data published on the development of the honeybee brain by S.M. Farris, G.E. Robinson, and S.E. Fahrbach (unpubl.).

In Drosophila, mushroom body neuroblasts undergo asymmetric cell divisions throughout larval stages and during pupal stages until almost the end of metamorphosis (Ito and Hotta 1992). However, in the optic lobes of Drosophila, like in the optic lobes of Apis, neuroblasts first divide symmetrically to produce a large number of stem cells, whereas the later neuroblasts divide in a typical asymmetrical fashion (Truman et al. 1993). This seems to indicate that symmetrical cell division predominantly takes place when a large number of neuroblasts needs to be generated over a short period of time.

According to the proposed pattern of proliferation of Kenyon precursor cells in honeybees, large origin Kenyon cell neuroblasts would lie among, and be indistinguishable from, the other large neuroblasts in the periphery of the protocerebrum for a very short period, that is, before they start to divide and then disappear. The total number of these protocerebral neuroblasts appears to be rather constant ( 40 per hemisphere) in early postembryonic stages, throughout larval stages 1 and 2, and even after the two proliferation centers of each mushroom body have been formed (stage $3)$. If the mushroom proliferation center would derive from a large subpopulation of these stem cells, it should be expected that the latter disappear as soon as they start their symmetrical cell division (see above). This would diminish the total number of these large conspicious neuroblasts. How ever, such a decrease was not observed. The loss of a very small number of stem cells (e.g., their conversion into small neuroblasts) would not be discovered by cell counts. The present study therefore suggests that Kenyon cells are generated by a very small number of large origin neuroblasts like in another holometabolous insect, the butterfly Danaus, where cell divisions of Kenyon cell neuroblasts were found to take place within two proliferation clusters (in each side of the brain), each of which were show $n$ to derive from three large neuroblasts, respectively (Nordlander and Edwards 1970). The data gathered with the ablation tech- nique further support the notion of a similar situation in the honeybee.

\section{HYDROXYUREA ABLATES COMPLETE MUSHROOM BODY SUBSTRUCTURES}

This study demonstrates that hydroxyurea applied to honeybees at larval stage 1 leads to specific ablations within the mushroom bodies. Although the defects varied in detail (summarized in Fig. 6), the prevalent feature $w$ as the complete deletion of individual mushroom body subunits, whereas the persisting subunits retained their overall shape and size. These findings can be explained in conjunction with the results of the BrdU study and histological data: During early larval development, the medial proliferation centers of Kenyon cell precursors appeared about one larval stage earlier than the lateral cell clusters. Therefore, cell proliferation of the stem cells forming the medial proliferation centers is likely to start before proliferation of the cells producing the lateral cluster. Immediately after their appearance, both clusters are characterized by their structural integrity producing two clearly separate units although they are not delimited by a continuous glial sheath (Hähnlein and Bicker 1997).

In this context, two striking features of the hydroxyurea experiments have to be mentioned: (1) Ninety-four percent of the animals displaying hydroxyurea-induced mushroom body defects showed complete ablations of mushroom body subunits even when the hydroxyurea concentration was reduced to threshold concentrations $(0.5$ $\mathrm{mg} / \mathrm{ml}$ ). Smaller or rudimentary mushroom bodies were observed in just very rare occasions ( 2 out of 36 animals). In these animals, some small Kenyon cell neuroblasts probably escaped hydroxyurea ablation and formed a small number of Kenyon cells. (2) Mushroom body ablation or reduction predominantly affected the medial calyces. One hundred percent of the animals exhibit mushroom body ablation of one or both medial calyces, whereas in $20 \%$ of the animals, one or both lateral clayces were missing.

These findings together with the above-mentioned histological data suggest that each cell cluster arises from separate stem cells. Consequently, in animals exhibiting only one mushroom body subunit in each hemisphere, this remaining subunit is not a merged structure but is rather generated by Kenyon cell precursors of a single prolif-

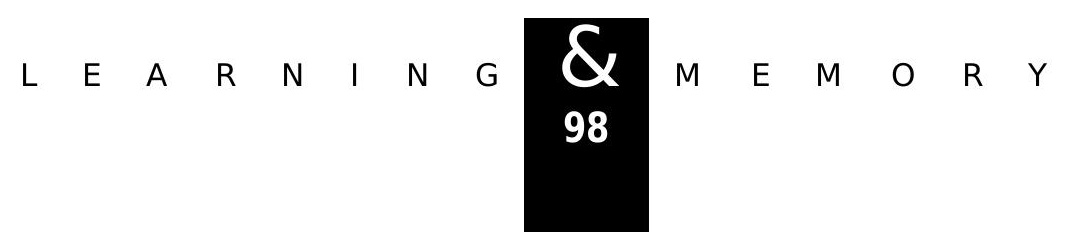


eration cluster. This further strengthens the idea that the tw o cell clusters develop functionally separately and that intercellular interactions between them, that is, exchange of cells, does not occur. After ablation of one mushroom body subunit, the calyx neuropil of the remaining mushroom body subunit just seems to take over freed space within the protocerebrum. Thereby, the calyx gives up its prominent cup-shaped structure and gets a flatter appearance. Yet, as a result of the ablation of one mushroom body subunit, the protocerebrum is clearly diminished in volume and so are the $\alpha$ - and $\beta$-lobes. The high incidence of animals with $a b$ lated medial mushroom bodies also shows that hydroxyurea applied to newly hatched larvae mainly affected stem cells of the medial cell cluster, whereas the stem cells forming the lateral cell cluster escaped ablation. This finding is compatible with an earlier onset of proliferative activity that leads to the medial cell cluster and, ultimately, the medial calyx. Although they were observed in very rare occasions ( $\mathrm{n}=2$ ) only, animals with complete mushroom body ablation suggest that the periods during which origin neuroblasts of the medial and the lateral calyces proliferate can overlap. About half of the population of animals with mushroom body ablation exhibit asymmetrical defects where the two sides of the brain differ with respect to the number of mushroom body subunits present (Figs. 5 and 6). Animals with such defects (Fig. 5B,D,E) underline the "all-or-none" character of the ablations induced by hydroxyurea. They strongly suggest that mushroom body subunits originate from a small number of Kenyon stem cells, possibly a single neuroblast, respectively. They also show that the hydroxyurea concentration applied was close to threshold.

Overall, it was surprising that the portion of animals with complete mushroom body ablation in this study was very small. How ever, the reason for this observation might be that only very low concentrations of hydroxyurea $(0.5-3.5 \mathrm{mg} / \mathrm{ml})$ lead to survival and hatching of imagines. As revealed by the BrdU study presented here, some stem cells including presumable Kenyon cell neuroblasts in the protocerebrum are mitotically active during larval stage 1, the stage hydroxyurea had been applied. Therefore, higher concentrations of hydroxyurea might have caused a higher incidence of complete mushroom body ablation but might have also affected other proliferating cells. The resulting damage throughout the brain might have led to lower survival rates.

\author{
COMPARISON TO THE MUSHROOM BODY \\ DEVELOPMENT IN DROSOPHILA
}

Organization and development of mushroom bodies in honeybees and Drosophila differ in many respects. Drosophila develop just one unpaired mushroom body with just one calyx and one peduncle per side of the brain. Each mushroom body consists of 2500 Kenyon cells only (Hinke 1961) in contrast to 170,000 in honeybees (Witthöft 1967). In Drosophila, each mushroom body is generated by four Kenyon cell neuroblasts (Ito and Hotta 1992), and each neuroblast is capable of forming autonomously all of the mushroom body structures (Ito et al. 1997). It was proposed that each of these neuroblasts produces a series of ganglion mother cells by asymmetrical divisions. The latter were thought to perform a single symmetrical cell division generating a pair of Kenyon cells. The large number of honeybee Kenyon cells cannot be accounted for by such a proliferation scheme: On the assumption of one neuroblast of 85,000 Kenyon cells per mushroom body subunit in the bee, this proliferation pattern would require 42,500 asymmetrical cell divisions by each neuroblast in $~ 310$ hr (13 days, larval stage 1 to pupal stage 4, e.g., 137 cell divisions per hour). This clearly cannot reflect the real situation even when assuming a greater number of origin neuroblasts per mushroom body subunit.

Hydroxyurea-induced defects are also different from ablations induced by hydroxyurea described for honeybees in this study. The effects of hydroxyurea in Drosophila depended on the concentration applied and ranged from partial to complete mushroom body ablation (de Belle and Heisenberg 1994; Ito et al. 1997). Low hydroxyurea concentrations led to survival of one or two of the four stem cells and consequently to smaller mushroom bodies (de Belle and Heisenberg 1994; Ito et al. 1997). In honeybees the prevalent effect of hydroxyurea application was the complete ablation of individual mushroom body subunits, whereas other subunits, in the same brain remained completely intact. Thus, mushroom body subunits in honeybees must originate from a very small number of neuroblasts as in Danaus or, more likely, just from one neuroblast (see above). Conversely, a greater number of neuroblasts per proliferation center should have caused small mushroom bodies like those described for Drosophila. Such defects, however, could not be found in the honeybee.

In summary, the results presented in this study

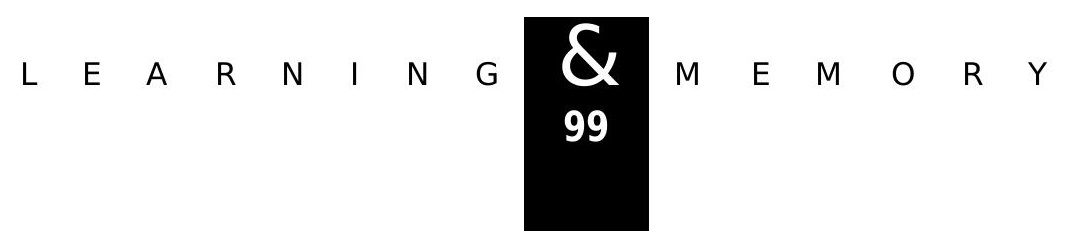


demonstrate that in honeybees each of the four mushroom body subunits develops postembryonically from a proliferation cluster containing Kenyon precursor cells that divide in a symmetrical fashion until mid-pupal stages. Cells within these mitotically active cell clusters derive possibly from a single origin Kenyon cell neuroblast, respectively.

The ablation experiments further showed that hydroxyurea treatment of young larvae induces specific and precise mushroom body defects. Therefore, this technique provides a promising tool to study the role of mushroom bodies for learning and memory in honeybees.

\section{Acknowledgments}

I gratefully acknowledge the financial support of $\mathrm{Dr}$. Randolf Menzel. Dr. Uli Müller kindly provided the antiserum to PKAII. Dr. Sabine Schäfer kindly provided the specimen shown in Figure 4B. I also acknowledge the contribution of Dr. O Iga Ganeshina in preparing the specimen shown in Figure 4A. I thank Drs. Randolf Menzel, Sabine Schäfer, and Bernhard Zimmermann for constructive discussion and comments on the manuscript. This work was supported by a scholarship from the Kommission zur Förderung von Nachwuchswissenschaftlerinnen der Freien Universität Berlin.

The publication costs of this article were defrayed in part by payment of page charges. This article must therefore be hereby marked "advertisement" in accordance with 18 USC section 1734 solely to indicate this fact.

\section{References}

Barth, M. and M. Heisenberg. 1997. Vision affects mushroom bodies and central complex in Drosophila melanogaster. Learn. \& Mem. 4: 219-229.

Bertholf, L.M. 1925. The moults of the honeybee. J. Econom. Entomol. 242: 593-605.

Davis, R.L. 1993. Mushroom bodies and Drosophila learning. Neuron 11: 1-14.

Davis, R.L. and B. Dauwalder. 1991. The Drosophila dunce locus: Learning and memory in flies. Trends Genet. 7: 224-229.

de Belle, J.S. and M. Heisenberg. 1994. Associative odor learning in Drosophila abolished by chemical ablation of mushroom bodies. Science 263: 692-695.

Doe, C.Q. and C.S. Goodman. 1985. Early events in insect neurogenesis: I. Development and segmental differences in the pattern of neuronal precursor cell. Dev. Biol.

111: 193-205.

Durst, C., S. Eichmüller, and R. Menzel. 1994. Development and experience lead to increased volume of subcompartments of the honeybee mushroom body. Behav. Neural Biol. 62: 259-263.

Edwards, J.S. 1969. Postembryonic development and regeneration of the insect nervous system. Adv. Insect Physiol. 6: 97-137.

Erber, J., T. Masuhr, and R. Menzel. 1980. Localization of short-term memory in the brain of the bee, Apis mellifera. Physiol. Entomol. 5: 343-358.

Fahrbach, S.E., T. Giray, and G.E. Robinson. 1995a. Volume changes in the mushroom bodies of adult honey bee queens. Neurobiol. Learn. \& Mem. 63: 181-191.

Fahrbach, S.E., J.L. Strande, and G.E. Robinson. 1995b. Neurogenesis is absent in the brains of adult honey bees and does not explain behavioral neuroplasticity. Neurosci. Lett. 197: 145-148.

Hähnlein, I. and G. Bicker. 1997. Glial patterning during postembryonic development of central neuropiles in the brain of the honeybee. Dev. Genes Evol. 207: 29-41.

Hammer, M. 1993. An identified neuron mediates the unconditioned stimulus in associative learning in honeybees. Nature 366: 59-63.

Hammer, M. and R. Menzel. 1995. Learning and memory in the honeybee. J. Neurosci. 15: 1617-1630.

Heisenberg, M., A. Borst, S. Wagner, and D. Byers. 1985. Drosophila mushroom body mutants are deficient in olfactory learning. J. Neurogenet. 2: 1-30.

Hinke, W. 1961. Das relative Wachstum der Hirnteile von Culex pipiens, Drosophila melanogaster, und Drosophila-Mutanten. Z. Morphol. O kol. Tiere 50: 81-118.

Ito, K. and Y. Hotta. 1992. Proliferation pattern of postembryonic neuroblasts in the brain of Drosophila melanogaster. Dev. Biol. 149: 134-148.

Ito, K., W. Awano, K. Suzuki, Y. Hiromi, and D. Yamamoto. 1997. The Drosophila mushroom body is a quadruple structure of clonal units each of which contains a virtually identical set of neurones and glial cells. Development 124: 761-771.

Kenyon, F.C. 1896. The brain of the bee. J. Comp. Neurol. 6: 133-210.

Malun, D. 1997. Postembryonic neurogenesis and development of the mushroom bodies in the honeybee. In Proceedings of the 25th Göttingen Neurobiology Conference (ed. N. Elsner and H. Wässle). Thieme, Stuttgart, Germany.

Mauelshagen, J. 1993. Neural correlates of olfactory learning in an identified neuron in the honeybee brain. J. Neurophysiol. 69: 609-625.

Menzel, R., J. Erber, and T. Masuhr. 1974. Learning and memory in the honeybee. In Experimental analysis of insect 
behaviour (ed. L. Barton-Browne), pp. 195-217. Springer, Berlin, Germany.

Menzel, R., C.D. Durst, J. Erber, S. Eichmüller, M. Hammer, H. Hildebrand, J. Mauelshagen, U. Müller, H. Rosenboom, J. Rybak, S. Schäfer, and A. Scheidler. 1994. The mushroom bodies in the honeybee: From molecules to behaviour. Fortschritte der Zoologie 39. In Neural basis of behavioural adaptions (ed. K. Schildberger and N. Elsner), pp. 81-102. Fischer, Stuttgart, Germany.

Mobbs, P.G. 1982. The brain of the honeybee Apis mellifera. I. The connections and spatial organization of the mushroom bodies. Phil. Trans. R. Soc. Lond. B. Biol. Sci. 298: 309-354.

M üller, U. 1997. N euronal CAM P-dependent protein kinase type II is concentrated in mushroom bodies of Drosophila melanogaster and the honeybee Apis mellifera. J. Neurobiol. 33: 33-44.

Nordlander, R.H. and J.S. Edwards. 1970. Postembryonic brain development in the monarch butterfly, Danaus plexippus plexippus L. III. M orphogenesis of centers other than the optic lobes. Wilhelm Roux's Arch. 164: 247-260.

Panov, A.A. 1957. Bau des Insektengehirns während der postembryonalen Entwicklung. Rev. Entomol. URSS 36: 269-284.

- - . 1960. Bau des Insektengehirns während der postembryonalen Entwicklung. III: Sehlappen. Rev. Entomol. URSS 39: 86-105.

Prokop, A. and G.M. Technau. 1994. Normal function of the mushroom body defect gene of Drosophila is required for the regulation of the number and proliferation of neuroblasts.

Dev. Biol. 161: 321-337.

Rybak, J. and R. Menzel. 1993. Anatomy of the mushroom bodies in the honey bee brain: The neuronal connections of the alpha-lobe. J. Comp. Neurol. 334: 444-465.

Skoulakis, E.M.C., D. Kalderon, and R.L. Davis. 1993. Preferential expression in mushroom bodies of the catalytic subunit of protein kinase $A$ and its role in learning and memory. Neuron 11: 197-208.

Technau, G. and M. Heisenberg. 1982. Neural reorganization of the corpora pedunculata in Drosophila melanogaster. Nature 295: 405-407.

Tettamanti, M., J.D. Armstrong, K. Endo, M.Y. Yang, K. Furukubo-Tokunaga, K. Kaiser, and H. Reichert. 1997. Early development of the Drosophila mushroom bodies, brain centres for associative learning and memory. Dev. Genes Evol. 207: 242-252.

Truman, J.W. and R. Booker. 1986. Adult-specific neurons in the nervous system of the moth, Manduca sexta: Selective chemical ablation using hydroxyurea. J. Neurobiol.

17: 613-626.

Truman, J.W. and M. Bate. 1988. Spatial and temporal patterns of neurogenesis in the central nervous system of Drosophila melanogaster. Dev. Biol. 125: 145-157.

Truman, J.W., B.J. Taylor, and T.A. Awad. 1993. Formation of the adult nervous system. In The development of Drosophila melanogaster (ed. M. Bate and A. Martinez-Arias), pp. 1245-1275. Cold Spring Harbor Laboratory Press, Cold Spring Harbor, NY.

Withers, G.S., S.E. Fahrbach, and G.E. Robinson. 1993. Selective neuroanatomical plasticity and division of labour in the honey bee. Nature 364: 238-240.

Witthöft, W. 1967. Absolute Anzahl und Verteilung der Zellen im Hirn der Honigbiene. Z. Morphol. Tiere 61: $160-184$.

Zacharias, D., J.L.D. Williams, T. Meier, and H. Reichert. 1993. Neurogenesis in the insect brain: Cellular identification and molecular characterization of brain neuroblasts in the grasshopper embryo. Development 118: 941-955.

Received January 28, 1998; accepted in revised form April 14, 1998. 


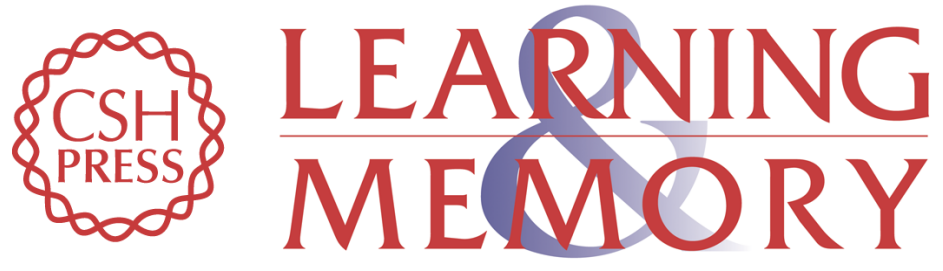

\section{Early Development of Mushroom Bodies in the Brain of the Honeybee Apis mellifera as Revealed by BrdU Incorporation and Ablation Experiments}

Dagmar Malun

Learn. Mem. 1998, 5:

Access the most recent version at doi:10.1101//m.5.1.90

References This article cites 34 articles, 5 of which can be accessed free at: http://learnmem.cshlp.org/content/5/1/90.full.html\#ref-list-1

License

Email Alerting

Receive free email alerts when new articles cite this article - sign up in the box at the Service top right corner of the article or click here. 